\title{
Zastosowanie modeli grawitacyjnych dla wybranych zbóż w handlu między UE a USA ${ }^{3}$
}

\section{Application of Gravity Models for Selected Cereals in EU - US Trade}

\begin{abstract}
Synopsis. Niniejszy artykuł przedstawia zastosowanie modeli grawitacyjnych w bilateralnym handlu takimi artykułami rolnymi jak: pszenica, owies i kukurydza między UE a USA. Analiza obejmowała lata 2000-2016, a w skład zmiennych objaśniających weszły PKB, wskaźnik PSE, wartość dodana w rolnictwie oraz wartość dodana na pracownika w rolnictwie. Przeprowadzone badania wykazały występowanie znacznych zakłóceń w wymianie handlowej wybranymi produktami rolnymi pomiędzy UE i USA. W konsekwencji model grawitacyjny zastosowany dla pszenicy, owsa i kukurydzy nie potwierdził, że masy gospodarek wyrażone w ich realnym PKB przyciagają się i umacniają wymianę handlową. Zjawisko odpychania zauważono także dla wartości dodanych w rolnictwie. Badania pozwoliły natomiast wykazać, iż wsparcie rolnictwa tworzy efekty przyciagania handlu, dla pszenicy i owsa.
\end{abstract}

Słowa kluczowe: handel bilateralny, rolnictwo, model grawitacyjny, UE i USA

\begin{abstract}
This article presents the use of gravity models in bilateral trade in agricultural products such as wheat, oats and maize between the EU and the USA. The analysis covered the years 2000-2016, and the explanatory variables included GDP, PSE index, value added in agriculture and value added per employee in agriculture. The conducted research revealed significant disturbances in trade between selected EU and US agricultural products. Consequently, the gravity model applied to wheat, oats and maize did not confirm that the masses of economies expressed in their real GDP are attracting and strengthening trade. The phenomenon of repulsion was also noticed for added values in agriculture. However, the research has shown that agricultural support creates the effects of attracting trade, for wheat and oats.
\end{abstract}

Key words: bilateral trade, agriculture, gravity model, UE and US

JEL Classification: F130

\section{Wprowadzenie}

Relacje handlowe pomiędzy UE a USA budzą wiele kontrowersji z uwagi na ich wielkość oraz wspływ na funkcjonowanie całych sektorów w obu obszarach ekonomicznych. Znaczenie tych powiązań jest szczególnie istotne, gdy pod uwagę bierzemy tzw. rynki wrażliwe, a do takich niewątpliwie możemy zaliczyć produkty rolno-

\footnotetext{
${ }^{1}$ dr hab. inż., prof. UZ, Wydział Ekonomii i Zarządzania, Katedra Ekonomii Międzynarodowej, e-mail: p.kulyk@wez.uz.zgora.pl; https://orcid.org/0000-0003-2786-4020

${ }^{2}$ mgr, Wydział Ekonomii i Zarządzania, Katedra Ekonomii Międzynarodowej,

e-mail: l.augustowski@wez.uz.zgora.pl; https://orcid.org/0000-0001-7212-4115

${ }^{3}$ Zrealizowano przy pomocy finansowej Miasta Zielona Góra.
} 
spożywcze. W tym przypadku na wymianę handlową i jej rezultaty wpływają rozbudowane polityki rolne, w tym zróżnicowane instrumentarium wsparcia czy stosowane regulacje w UE i USA. Podejmowane są liczne próby wzajemnego uregulowania tej wymiany czy to w postaci multilateralnej (m.in. w ramach GATT, a następnie konferencji ministerialnych) czy też bilateralnych (m.in. podjęta próba całościowego unormowania handlu w postaci jednej rozbudowanej umowy handlowej - TTIP). Zachodzace nieustannie przemiany w regulacjach handlowych, zmiany $w$ politykach rolnych, a także w całej globalnej wymianie produktami rolnymi sprawiaja, iż pozycja konkurencyjna każdej ze stron rozważanych relacji jest uwarunkowana licznymi czynnikami i również podlega zmianom, co rodzi potrzebę jej permanentnego analizowania z różnej perspektywy. Wychodząc naprzeciw tym przesłankom celem artykułu było określenie siły oddziaływania czynników związanych z procesem globalizacji na wielkość przepływów handlowych wybranych produktów rolnych między UE jako całością a USA. Autorzy poszukiwali odpowiedzi na pytanie: czy występują siły przyciagające, czy raczej odpychające w handlu wybranymi produktami rolnymi na linii UE-USA? W analizie wykorzystano modele grawitacyjne handlu dla lat 2000-2016.

\section{Relacje między UE a USA}

Zarówno USA jak i UE stanowią jedne z największych gospodarek światowych. Dzięki realizacji bilateralnego modelu handlu mogą uzyskiwać dodatkowe korzyści $\mathrm{z}$ wymiany towarowej. W związku z tym, że obie gospodarki nie tworzą między sobą strefy wolnego handlu, a wymiana handlowa jest poddana szerokiej grupie czynników instytucjonalnych. Powstanie takiej instytucjonalnej formy integracji, kształtuje korzystne efekty kreacji i przesunięcia handlowego, co było i jest impulsem do poszukiwania działań sprzyjających intensyfikacji wymiany handlowej. W efekcie, tego od 2013 r. trwały negocjacje na linii UE-USA dotyczące transatlantyckiego partnerstwa handlowoinwestycyjnego (TTIP). Jednym z zakładanych celów TTIP było wspieranie inwestycji i działań handlowych po obu stronach Atlantyku, zwiększenie zatrudnienia i konkurencyjności oraz wypracowanie wspólnego podejścia do zasady handlu światowego. Wdrożenie TTIP miało sprzyjać ściślejszym powiązaniom gospodarczym i inwestycyjnym między UE a USA. Istnieją trzy podstawowe obszary negocjacji, do których zaliczono poprawę dostępu do rynku na zasadzie wzajemności, ograniczenie barier pozataryfowych i zwiększenie kompatybilności systemów regulacyjnych oraz ustanowienie zasad rozwiązywania wspólnych problemów i wykorzystywania możliwości handlu światowego (Poczta-Wajda, Sapa, 2017).Liberalizacja handlu powinna umożliwić stronom zwiększenie przewagi wobec krajów BRIC (Brazylia, Rosja, Indie, Chiny) oraz uniezależnić ich gospodarki od niestabilności wschodzących rynków (Czarny, Menkes, Śledziewska, 2014). Wiele aspektów miało potwierdzać taki pozytywny scenariusz negocjacji na linii UE-USA. Zarówno UE jak i USA doświadczyły zaledwie nieznacznego wzrostu od czasu kryzysu finansowego z 2008 roku. Nie mając jeszcze dość możliwości stosowania luzowania polityki fiskalnej i monetarnej, zwracają się one w stronę reform strukturalnych. W przeciwieństwie do krajowych reform rynku pracy lub rynku produktów, zwraca się uwagę na liberalizację handlu i korzyści z niej wynikających. Po drugie, wielotorowe rozmowy handlowe w Doha organizowane przez Światową Organizację Handlu (WTO) nie zakończyły się sukcesem, pomimo 12 lat negocjacji. Kwestie handlowe stały się coraz 
bardziej złożone i przeszły od prostych scenariuszy redukcji taryf do znacznie bardziej skomplikowanych problemów związanych licznymi regulacjami. Po trzecie, liderzy zarówno w UE jak i USA zauważają, że zmniejszenie tarć w handlu między ich regionami jest ważnym sposobem odzyskania części utraconej przez siebie konkurencyjności w stosunku do krajów wschodzących, takich jak Chiny i Indie (Felbermayr i Larch, 2013). Jak jednak zauważa Marciniuk (2013), w całej historii negocjacji na linii UE-USA, rolnictwo stanowiło jedno $\mathrm{z}$ najtrudniejszych zagadnień $\mathrm{i}$ często prowadziło do wstrzymywania rozmów na temat porozumień o zasięgu globalnym. W aspekcie długookresowym możemy wskazać zarówno korzyści jak i koszty z tytułu zawarcia tego typu porozumienia transatlantyckiego (tab. 1). Umowa TTIP nie została ostatecznie parafowana, jednak $\mathrm{z}$ uwagi na znaczenie wymiany handlowej produktami rolnymi pomiędzy UE i USA otwartym pozostaje pytanie jak ostatecznie wpłynęłaby na ten obszar?

Tabela 1. Potencjalne korzyści i koszty wynikające z zawarcia porozumienia TTIP między USA i UE

Table 1. Potential benefits and costs resulting from the TTIP agreement between the US and the EU

\begin{tabular}{l|l}
\hline \multicolumn{1}{c|}{ Korzyści } & \multicolumn{1}{c}{ Koszty } \\
\hline $\begin{array}{l}\text { Dostęp do nowego rynku } \\
\text { Możliwość wystapienia konwergencji w zakresie } \\
\text { regulacji prawnych }\end{array}$ & Zakłócenia rynku \\
Harmonizacja działań w polityce gospodarczej & Nierówne warunki w prowadzeniu handlu \\
\hline
\end{tabular}

Źródło: opracowanie własne na podstawie: Krzyżanowski J. (2016). Szanse $i$ zagrożenia dla rolnictwa i konsumentów żywności $w$ krajach Unii Europejskiej wynikajace z ewentualnego porozumienia TTIP, Zagadnienia Ekonomiki Rolnej, 3(348).

Kryteria kosztowe, poza zakłóceniami rynku mogą wynikać także z różnic w pojmowaniu rolnictwa między UE a USA. Dotyczy to zarówno poglądów na rolę i miejsce rolnictwa, postrzeganiu rolnictwa, stosunku konsumentów do produktów rolnych a także występujących regulacji prawnych (tab. 2).

Tabela 2. Różnice w postrzeganiu rolnictwa między UE i USA

Table 2. Differences in the perception of agriculture between the EU and the US

\begin{tabular}{|c|c|c|}
\hline Kryterium & USA & UE \\
\hline $\begin{array}{l}\text { Poglądy na rolę i miejsce } \\
\text { rolnictwa }\end{array}$ & $\begin{array}{l}\text { Marginalne znaczenie } \\
\text { pozaekonomicznych funkcji rolnictwa }\end{array}$ & Wielofunkcjonalność rolnictwa \\
\hline Postrzeganie rolnictwa & $\begin{array}{l}\text { Ochrona środowiska raczej poprzez } \\
\text { programy odłogowania }\end{array}$ & $\begin{array}{l}\text { Istotny element ochrony środowiska, } \\
\text { promocja rolnictwa }\end{array}$ \\
\hline $\begin{array}{l}\text { Stosunek do produktów } \\
\text { żywnościowych }\end{array}$ & Bezpieczeństwo i cena żywności & $\begin{array}{l}\text { Produkcja związana jest z tradycją, } \\
\text { kulturą i danym miejscem. } \\
\text { Nastawienie na specjalizację }\end{array}$ \\
\hline Regulacje prawne & $\begin{array}{l}\text { Zaufanie do różnych sposobów } \\
\text { przetwarzania żywności }\end{array}$ & Obawy przed GMO \\
\hline
\end{tabular}

Źródło: opracowanie własne na podstawie: Marciniuk K. (2013). Problematyka rolna w świetle nowej umowy handlowej UE-USA (Transatlantic Trade \& Investment Agreement), Studia Iuridica Agraria T. 11., s. 232-234.

W ostatnich latach zmieniały się także struktury eksportu i importu produktami rolnymi między UE i USA. Podczas gdy w 2015 r. Stany Zjednoczone miały nadwyżkę w handlu zagranicznym tymi produktami w wysokości 16 miliardów dolarów z resztą świata, kraje UE odnotowały rekordowy deficyt handlowy w wysokości 12 miliardów USD w produktach rolno-spożywczych, o 15 procent większy w porównaniu z 2014 r. Dzięki 
silnemu popytowi ze strony USA na produkty unijne, w 2015 roku Stany Zjednoczone przeznaczyły rekordową sumę 25 miliardów dolarów na importowaną żywność i produkty rolne. Tymczasem amerykański eksport do UE spadł o cztery procent do prawie 13 miliardów dolarów. Przez większą część ostatniej dekady rosnący popyt konsumpcyjny w UE pomógł zwiększyć eksport USA. Jednak w ostatnich latach eksport produktów rolnych z USA rósł wolniej niż import z Europy[fas.usda.gov].

\section{Zastosowanie modelu grawitacyjnego handlu do oceny relacji wymiany bilateralnej produktami rolnymi}

Teoria wymiany międzynarodowej sugeruje, że kraje uczestniczące $\mathrm{w}$ wymianie handlowej będą odnosiły znaczące korzyści, niż w przypadku, gdyby taka wymiana w ogóle nie istniała. Wiąże się to poprawą efektywności alokacji zasobów. Analizując powiązania handlowe między grupą krajów, oprócz stosunkowo prostych wskaźników makroekonomicznych jak: eksport, import, eksport netto czy stopień otwartości gospodarki, warto także poddać analizie siły przyciągające i odpychające w relacjach handlowych. Głównym narzędziem w ocenie takich relacji jest model grawitacyjny. Idea modelu grawitacyjnego została zaproponowana przez Tinbergena (1962), a jej inspiracją było sformułowanie przez Newtona prawa powszechnego ciażenia. Odtąd model grawitacji stał się popularnym instrumentem $\mathrm{w}$ empirycznej analizie handlu zagranicznego. Znalazł on szerokie zastosowanie analizie różnego typu przepływów, takich jak: handel, migracja czy bezpośrednie inwestycje zagraniczne. Zgodnie z modelem przepływy z kraju $i$ do kraju $j$ sa wyjaśniane ich wielkościami ekonomicznymi (PKB), populacjami, bezpośrednimi odległościami geograficznymi i zestawem cech instytucjonalnych (Martinez-Zarzoso, Nowak-Lehmann, 2003). Jak jednak zauważają Drzewoszewska, Pietrzak i Wilk (2013) modele grawitacyjne dopuszczają szerszy zakres zmiennych zarówno objaśniających oraz inną zmienną objaśnianą. Dało to możliwości szacowania wpływu potencjalnych czynników nie tylko na wielkości handlu, ale także bezpośrednich inwestycji zagranicznych (Szczepkowska, Wojciechowski, 2002).Ponadto, taka modyfikacja zwiększa użyteczność zastosowania modeli grawitacyjnych $\mathrm{w}$ badaniach regionalnych i międzynarodowych. Pozwala bowiem wprowadzić dodatkowe uwarunkowania w postaci kolejnych zmiennych korygujących. Dzięki temu model został z powodzeniem zastosowany w celu wyjaśnienia czynników wpływających na różne rodzaje przepływów, takich jak migracja, napływ nabywców do centrów handlowych, ruch rekreacyjny lub przepływy pacjentów do szpitali. W kontekście międzynarodowym, model grawitacji był dobrze dostosowany do analizy polityki handlowej, a zatem był szeroko stosowany jako punkt odniesienia do oszacowania wpływu różnych kwestii ekonomicznych oraz politycznych na regionalne grupy handlowe, związki walutowe i różne zakłócenia w handlu (Serlenga i Shin, 2004). Model ten sprawdził się także $\mathrm{w}$ analizie migracyjnej wskazując, że siła przyciagająca między imigrantami a krajami docelowymi zależy od różnicy między dochodami z pracy $\mathrm{w}$ obu krajach. Wskazano także na znaczenie wielkości populacji. Im więcej osób jest w kraju pochodzenia, tym więcej osób może migrować, a im większa populacja w kraju docelowym, tym większy jest rynek pracy dla imigrantów. Podobnie jak w przypadku handlu, koszty migracji powinny być skorelowane z fizyczną odległością między krajami (Lewer i van den Berg, 2008). W standardowym ujęciu modelu grawitacyjnego zakłada się, że szoki ekonomiczne mogą się znacznie różnić w zależności od masy gospodarki 
w miejscu pochodzenia oraz przeznaczenia, a także w zależności od odległości między miejscem pochodzenia a gospodarką przeznaczenia (Anderson, 2016). Można to wyrazić za pomocą następującego równania (Burger, van Oort i Linders, 2009):

gdzie:

$$
I_{i j}=K \frac{M_{i}^{\beta 1} M_{j}^{\beta 2}}{d_{i j}^{\beta 3}}
$$

$\mathrm{I}_{i j}$-jest wolumenem wymiany handlowej między krajami $i$ oraz $j$,

$\mathrm{K}$ - jest stałą,

$\mathrm{M}_{i}$-jest masą kraju pochodzenia (i), zazwyczaj wyrażaną jako PKB

$\mathrm{M}_{j}$ - jest masą kraju przeznaczenia $(j)$,

$\mathrm{D}_{i j}$ - jest fizyczną odległością między dwoma krajami,

$\beta 1$ - jest potencjałem do generowania przepływów,

$\beta 2$ - jest potencjałem przyciagania przepływów,

$\beta 3$ - jest odzwierciedleniem spadku odległości w ramach wymiany handlowej.

Późniejsze prace rekomendowały rozszerzenie modelu podstawowego przez uzupełnienie równania o dodatkowe zmienne objaśniające, które mogły w istotny sposób wpłynać na stosunki handlowe. Dopełniono więc zestaw zmiennych o takie jak: wspólny język, różnice kulturowe, bariery komunikacyjne (Klimczak, 2015) a także przynależność do ugrupowań integracyjnych czy znaczenie efektu granicy (Pietrzak i Łapińska,2014). Modele grawitacyjne zostały także licznie wykorzystywane do oceny relacji handlowych produktami rolnymi. W pracy Opler'a i Raimondi (2008) wykorzystano oszacowanie efektu granicy w oparciu o model grawitacji, aby ocenić poziom integracji handlu rynkiem rolnym między 22 krajami OECD w okresie 1994-2003. Analiza empiryczna potwierdziła wówczas, że wykorzystanie równania grawitacyjnego w ocenie efektu granicy, ma znaczenie $\mathrm{w}$ analizie relacji wymiany handlowej. Reprezentatywne oszacowanie efektu granicy ukazało, że przekroczenie granicy krajowej w ramach OECD wywołuje efekt redukcji handlu. Konwencjonalny model grawitacji został także zrewidowany dla jednego towaru i zastosowany do rynków mięsa w celu określenia czynników wpływających na przepływy handlowe mięsa. W badaniach wskazano na takie zmienne jak: liczba zwierząt, dystans fizyczny, subsydia dla producentów i kontyngenty importowe (Koo, Karemera, Taylor, 1994). W badaniach Hatab'a, Romstad'a i Huo (2010) wykorzystano podejście oparte na modelu grawitacyjnym, aby przeanalizować główne czynniki wpływające na relacje handlowe produktami rolnymi Egiptu do jego głównych partnerów handlowych w latach 1994-2008. Do analizy wykorzystano takie zmienne jak PKB per capita, PKB, otwartość gospodarki oraz zmiany kursów walutowych. Stwierdzono ponadto, że koszty transportu, w zależności od odległości, mają negatywny wpływ na eksport produktów rolnych. Wskazano także, że wyniki te są ważne dla sformułowania polityki handlowej w celu promowania egipskiego eksportu produktów rolnych na rynek światowy. Analizując rynek rolny, warto zauważyć, że różni się on od typowego rynku produktów. Dlatego w modelu grawitacyjnym, uwzględniającym wybrane produkty rolne $\mathrm{w}$ bilateralnym handlu między USA i UE wybrano następujące zmienne objaśniające: PKB per capita w obu krajach (GDP), wartość dodaną w rolnictwie (AVA), wartość dodaną na pracownika 
(AVApw) oraz wskaźnik wsparcia producentów rolnych (PSE) ${ }^{4}$. Zmienną objaśnianą były wielkości eksportu produktów rolnych: pszenicy, owsa i kukurydzy. Wybór był podyktowany znaczeniem produktów w wymianie oraz standardowym charakterem produktów (spełniającym warunek jednorodności). Model estymowano metodą OLS po uprzedniej transformacji zmiennych do postaci log-log. Analiza obejmuje lata 2000-2016. Ze względu na stałą odległość między dwoma gospodarkami w modelu pominięto zmienną dystansowa. W przypadku występowania niskiej istotności statystycznej usuwano wybrane zmienne a posteriori. Wyniki estymacji przedstawiają tabele 3-5.

Tabela 3. Bilateralny model grawitacyjny pszenicy

Table 3. Bilateral gravitational model of wheat

\begin{tabular}{|c|c|c|c|c|c|}
\hline Czynnik & Współczynnik & Błąd stand. & t-Studenta & Wartość p & \\
\hline Const & 336,741 & 148,245 & 2,272 & 0,0492 & $* *$ \\
\hline GDPE & 173,668 & 45,1989 & 3,842 & 0,0040 & $* * *$ \\
\hline GDPU & $-162,541$ & 39,5367 & $-4,111$ & 0,0026 & $* * *$ \\
\hline AVAE & $-15,3178$ & 9,41527 & $-1,627$ & 0,1382 & \\
\hline AVApwE & $-28,1873$ & 11,8524 & $-2,378$ & 0,0414 & $* *$ \\
\hline PSEU & 12,7763 & 5,61508 & 2,275 & 0,0489 & $* *$ \\
\hline PSEE & 16,2177 & 8,02257 & 2,022 & 0,0739 & $*$ \\
\hline \multicolumn{6}{|c|}{ Testy statystyczne modelu } \\
\hline Średn. aryt. zm. zależnej & 14,08399 & \multicolumn{2}{|c|}{ Odch. stand. zm. zależnej } & & 2,299922 \\
\hline Suma kwadratów reszt & 20,98838 & \multicolumn{2}{|c|}{ Błąd standardowy reszt } & & 1,527103 \\
\hline Wsp. determ. R-kwadrat & 0,735478 & \multicolumn{2}{|c|}{ Skorygowany R-kwadrat } & & 0,559130 \\
\hline
\end{tabular}

Oznaczenia: *** - istotność na poziomie $0,01 \%$,** - istotność na poziomie $0,05 \%$, * istotność na poziomie $0,1 \%$.

Źródło: opracowanie własne na podstawie programu Gretl, na podstawie danych Eurostatu.

Tabela 4. Bilateralny model grawitacyjny owsa

Table 4. Bilateral gravitational model of oats

\begin{tabular}{|c|c|c|c|c|c|}
\hline Czynnik & Współczynnik & \multicolumn{2}{|c|}{ Błąd stand. } & t-Studenta & wartość p \\
\hline Const & 72,5831 & \multicolumn{2}{|c|}{78,1458} & 0,9288 & 0,3772 \\
\hline GDPE & 12,0427 & \multicolumn{2}{|c|}{13,5344} & 0,8898 & 0,3967 \\
\hline GDPU & $-16,3757$ & \multicolumn{2}{|c|}{14,6803} & $-1,115$ & 0,2935 \\
\hline AVAE & $-6,00657$ & \multicolumn{2}{|c|}{5,70376} & $-1,053$ & 0,3198 \\
\hline AVAU & 3,05681 & \multicolumn{2}{|c|}{2,98361} & 1,025 & 0,3323 \\
\hline PSEU & 3,82253 & \multicolumn{2}{|c|}{2,09493} & 1,825 & 0,1014 \\
\hline PSEE & 2,90197 & \multicolumn{2}{|c|}{3,77923} & 0,7679 & 0,4622 \\
\hline \multicolumn{6}{|c|}{ Testy statystyczne modelu } \\
\hline Średn. aryt. zm. zależnej & \multicolumn{2}{|c|}{16,62774} & \multicolumn{2}{|c|}{ Odch. stand. zm. zależnej } & 1,064279 \\
\hline Suma kwadratów reszt & \multicolumn{2}{|c|}{5,661206} & \multicolumn{2}{|c|}{ Błąd standardowy reszt } & 0,793110 \\
\hline Wsp. determ. R-kwadrat & \multicolumn{2}{|c|}{0,666799} & \multicolumn{2}{|c|}{ Skorygowany R-kwadrat } & 0,444664 \\
\hline$F(6,9)$ & \multicolumn{2}{|c|}{3,001783} & \multicolumn{2}{|c|}{ Wartość p dla testu F } & 0,067613 \\
\hline Logarytm wiarygodności & \multicolumn{2}{|c|}{$-14,39140$} & \multicolumn{2}{|c|}{ Kryt. inform. Akaike'a } & 42,78280 \\
\hline Kryt. bayes. Schwarza & \multicolumn{2}{|c|}{48,19093} & \multicolumn{2}{|c|}{ Kryt. Hannana-Quinna } & 43,05974 \\
\hline Autokorel.reszt - rho1 & \multicolumn{2}{|c|}{0,192808} & \multicolumn{2}{|c|}{ Stat. Durbina-Watsona } & 1,479917 \\
\hline
\end{tabular}

Źródło: opracowanie własne na podstawie programu Gretl, na podstawie danych Eurostatu.

${ }^{4}$ Ostatnie litery w zmiennych oznaczają odpowiednio: E - dla Unii Europejskiej; U - Dla USA. 
Tabela 5. Bilateralny model grawitacyjny kukurydzy

Table 5. Bilateral gravity model of corn

\begin{tabular}{l|cccc}
\hline \multicolumn{1}{c|}{ Czynnik } & Współczynnik & Błąd stand. & t-Studenta & wartość p \\
\hline const & $-45,6949$ & 56,3056 & $-0,8116$ & 0,4380 \\
GDPE & $-13,3768$ & 12,4175 & $-1,077$ & 0,3094 \\
GDPU & 11,6833 & 13,1064 & 0,8914 & 0,3959 \\
AVAE & $-2,28266$ & 2,79858 & $-0,8156$ & 0,4358 \\
AVAU & 4,96980 & 2,73444 & 1,817 & 0,1025 \\
AVApwE & 6,64283 & 4,84748 & 1,370 & 0,2038 \\
AVApwU & $-5,72660$ & 3,16767 & $-1,808$ & 0,1041 \\
\hline & \multicolumn{3}{c}{ Testy statystyczne modelu } & 1,061925 \\
Średn. aryt. zm. zależnej & 15,41270 & Odch. stand. zm. zależnej & 0,855787 \\
Suma kwadratów reszt & 6,591348 & Błąd standardowy reszt & 0,350553 \\
Wsp. determ. R-kwadrat & 0,610332 & Skorygowany R-kwadrat & 0,120265 \\
F(6, 9) & 2,349429 & Wartość p dla testu F & 45,21674 \\
Logarytm wiarygodności & $-15,60837$ & Kryt. inform. Akaike'a & 45,49368 \\
Kryt. bayes. Schwarza & 50,62486 & Kryt. Hannana-Quinna & 1,712837 \\
Autokorel.reszt - rho1 & 0,128228 & Stat. Durbina-Watsona & \\
\hline
\end{tabular}

Źródło: opracowanie własne na podstawie programu Gretl, na podstawie danych Eurostatu.

Model grawitacyjny zastosowany dla pszenicy, owsa i kukurydzy nie potwierdził przypuszczenia, że wielkości (masy) gospodarek wyrażone $w$ ich realnym PKB w obecnych warunkach wymiany handlowej przyciagają się i umacniają tę wymiane. Występuje raczej zjawisko jednostronnego odpychania dla PKB per capita. Podobna sytuację zauważono także dla wartości dodanych w rolnictwie. Przyjmując z kolei za masę wielkość wskaźnika PSE zaobserwowano, że wsparcie rolnictwa tworzy efekty przyciągania handlu, dla pszenicy i owsa. Zatem jest głównym elementem naruszającym mechanizm wymiany bilateralnej produktami rolnymi. W pozostałych przypadkach należy wskazać, iż był to czynnik zakłócający proces wymiany handlowej. Zjawisko takie można tłumaczyć tym, że USA posiada znaczne zasoby ziemi, dzięki czemu osiągają znaczą przewage $\mathrm{w}$ produkcji kukurydzy i pszenicy. Zjawisko to zdaje się thumaczyć brak obustronnego przyciagania gospodarek w ujęciu handlowym dla rolnictwa. Nie bez znaczenia są także występujące w rolnictwie regulacje w wymianie i produkcji rolnej, które mogą powodować występowanie zjawiska braku przyciagania w wymianie handlowej produktami rolnymi pomiędzy USA i UE.

\section{Podsumowanie}

Przeprowadzone badania wykazały występowanie znacznych zakłóceń w wymianie handlowej wybranymi produktami rolnymi pomiędzy UE i USA. W konsekwencji model grawitacyjny zastosowany dla pszenicy, owsa i kukurydzy nie potwierdził, że masy gospodarek wyrażone w ich realnym PKB przyciągają się i umacniają wymianę handlową. Zatem czynniki ekonomiczne ujmowane w klasycznym podejściu nie wyjaśniają mechanizmu i wielkości wymiany handlowej w rozważanych relacjach. Zjawisko odpychania zauważono także dla wartości dodanych w rolnictwie. Zatem problem nie tkwi w samej specyfice produkcji rolnej i jej znaczeniu w tworzeniu PKB. W konsekwencji 
uwarunkowania ekonomiczne związane z wielkością rynków i popytem konsumpcyjnym nie pozwalają wyjaśnić wielkości wymiany i jej wyniku netto.

Badania pozwoliły natomiast wykazać, iż wsparcie rolnictwa tworzy efekty przyciagania handlu, dla pszenicy i owsa. W pozostałych przypadkach należy wskazać, iż był to czynnik odpychający strumienie eksportu i importu. Na tej podstawie możemy stwierdzić, iż niezależnie od przesłanek jego ustanowienia i strukturalnego zróżnicowania był to główny czynnik zakłócający wymianę handlową między UE i USA. Dysproporcje w skali finansowego wsparcia na poszczególnych rynkach i ich wpływ na poziom cen krajowych powodował zróżnicowanie oddziaływanie na wymianę handlową (odpychanie lub przyciaganie). Zjawisko to równocześnie thumaczy brak obustronnego przyciagania gospodarek w zakresie strumieni wymiany handlowej.

\section{Literatura}

Anderson, J.E. (2016). The Gravity Model of Economic Interaction, Boston College and NBER.

Burger, M. J., van Oort, F., Linders, G-J. (2009). On the Specification of the Gravity Model of Trade: Zeros, Excess Zeros and Zero-inflated Estimation. Spatial Economic Analysis, 4(2), 167-171.

Czarny, E., Menkes, J., Śledziewska, K. (2014).Umowa o Partnerstwie Handlowo-Inwestycyjnym między Stanami Zjednoczonymi i Unią Europejską jako narzędzie międzynarodowej współpracy gospodarczej (Agreement on Trade and Investment Partnership between the United States and the European Union as a tool for international economic cooperation). International Business and Global Economy, 33, 199-213.

Drzewoszewska, N., Pietrzak, M. B., Wilk, J. (2013). Grawitacyjny model przepływów handlowych między krajami Unii Europejskiej w dobie globalizacji (Gravitational model of trade flows between the countries of the European Union in the era of globalization). Roczniki Kolegium Analiz Ekonomicznych, 30, 187-202.

Felbermayr, G.J., Larch, M. (2013). The Transatlantic Trade and Investment Partnership (TTIP): Potentials, Problems and Perspectives. CESifo Forum, 14(2), 49-60.

Hatab, A.A., Romstad, E., Huo, X. (2010). Determinants of Egyptian Agricultural Exports: A Gravity Model Approach. Modern Economy, 1, 134-143.

https://www.fas.usda.gov/data/eu-agricultural-exports-trade-surplus-us-reach-record-levels-2015.

Klimczak, Ł. (2015). Model grawitacyjny jako narzędzie analizy handlu zagranicznego (The gravitational model as a tool for analyzing foreign trade). ZN Uniwersytetu Ekonomicznego w Krakowie, 5(941), 107-130.

Koo, W. W., Karemera, D., Taylor, R. (1994). A gravity model analysis of meat trade policies. Agricultural Economics 10, 81-88.

Krzyżanowski J. (2016). Szanse i zagrożenia dla rolnictwa i konsumentów żywności w krajach Unii Europejskiej wynikające $\mathrm{z}$ ewentualnego porozumienia TTIP (Opportunities and threats for food and agriculture in European Union countries resulting from possible TTIP agrement). Zagadnienia Ekonomiki Rolnej, 3(348), 3-23.

Lewer, J. J., van den Berg, H. (2008). A Gravity Model of Immigration. Economics Letters, 99(1), 164-167.

Marciniuk, K. (2013). Problematyka rolna w świetle nowej umowy handlowej UE-USA (Transatlantic Trade \& Investment Agreement) (Agricultural issues in the light of the new EU-US trade agreement). Studia Iuridica Agraria, 11, 227-241.

Martinez-Zarzoso, I., Nowak-Lehmann, R. (2003). Augmented Gravity Model: An Empirical Application to Mercosur-European Union Trade Flows. Journal of Applied Economics, 6(2), 291-316.

Opler, A., Raimondi, V. (2008). Agricultural market integration in the OECD: A gravity-border effect approach. Food Policy, 33, 165-175.

Pietrzak, M. B., Łapińska, J. (2014). Zastosowanie modelu grawitacji do identyfikacji czynników determinujących przepływy handlowe w Unii Europejskiej (Application of the gravity model to identify factors determining trade flows in the European Union). Przeglad Statystyczny, 61(1), 65-77.

Poczta-Wajda, A., Sapa, A. (2017). Potential Trade Effects of Tariff Liberalization under the Transatlantic Trade and Investment Partnership (TTIP) for the UE Agri-Food Sector. Journal of Agribusiness and Rural Development, 2(44), 421-433.

Serlenga, L., Shin, Y. (2004). Gravity Models of the Intra-EU Trade: Application of the Hausman-Taylor Estimation in Heterogeneous Panels with Common Time-specific Factors, Far Eastern Meetings No. 671. Econometric Society. 
Szczepkowska, A., Wojciechowski, L. (2002). Możliwości wykorzystania modelu grawitacji do analizy bezpośrednich inwestycji zagranicznych w Polsce (Possibilities of using the gravity model for the analysis of foreign direct investment in Poland). W: red. Piech K., Szczodrowski G., Przemiany i perspektywy polskiej gospodarki w procesie integracji z gospodarką światową, Instytut Wiedzy, Warszawa, 267-282.

Tinbergen, J. (1962). Shaping the World Economy; Suggestions for an International Economic Policy. Twentieth Century Fund, New York.

Do cytowania / For citation:

Kułyk P., Augustowski Ł. (2018). Zastosowanie modeli grawitacyjnych dla wybranych zbóż w handlu między UE a USA. Problemy Rolnictwa Światowego, 18(4), 295-303;

DOI: $10.22630 / P R S .2018 .18 .4 .119$

Kułyk P., Augustowski Ł. (2018). Application of Gravity Models for Selected Cereals in EU - US Trade (in Polish). Problems of World Agriculture, 18(4), 295-303;

DOI: $10.22630 /$ PRS.2018.18.4.119 